\title{
El derecho al trabajo en la futura Constitución
}

Carlos Blancas Bustamante

La discusión acerca del contenido y alcances del «derecho al trabajo», reconocido por nuestro ordenamiento jurídico desde la Constitución de 1979 , ha venido a incentivarse en los últimos tiempos, básicamente por dos factores: 1) la sentencia del Tribunal Constitucional del 11 de julio del 2002 que interpreta este derecho, reconocido en el artículo $22^{\circ}$ de la Constitución de 1993, en un sentido amplio, esto es, comprensivo del derecho del trabajador a no ser despedido sino por justa causa, y 2) la elaboración de una nueva Constitución, en cuyo artículo $27^{\circ}$ se incluye en el derecho al trabajo la exigencia de causa justificada para el despido. ${ }^{1}$

Estos dos hechos, de innegable trascendencia para las relaciones laborales, en cuanto vienen a reforzar los mecanismos de tutela contra los despidos arbitrarios o incausados, tras una década de "reforma laboral" en que estos fueron impunemente consentidos, ameritan un estudio detenido del "derecho al trabajo" que luego de haber permanecido aletargado, acantonado por una interpretación restrictiva que lo relegaba al rol de mera norma programática privada de efectividad, cobra nueva vida al convertirse en fundamento de importantes mecanismos relacionados con el que es, quizás, el momento más trascendente de la relación laboral: el de su extinción.

Por esa razón, en este trabajo, pretendemos ahondar en el significado y contenido del «derecho al trabajo», tanto en su perspectiva histórica y teórica, como en los alcances de la formulación que del mismo hace el proyecto de la nueva constitución.

1 Proyecto de ley de Reforma de la Constitución, Comisión de Constitución, reglamento y acusaciones constitucionales, Congreso de la República, julio de 2002. 


\section{Panorama histórico: su reconocimiento constitucional e interna- cional.}

\section{Su reconocimiento en las «declaraciones de derechos" y las Constituciones}

En el proceso de formación y reconocimiento de los derechos de la persona, el "derecho al trabajo» no aparece mencionado en las primeras declaraciones o catálogos de derechos. En particular, debemos mencionar que la Declaración de Derechos del Hombre y del Ciudadano de la Revolución Francesa, ${ }^{2}$ no contiene ninguna referencia específica al trabajo ni, por cierto, a un "derecho al trabajo».

Suele considerarse el año 1848 , con ocasión de la revolución de febrero en Francia, la oportunidad histórica en que, por primera vez, se enuncia el "derecho al trabajo" ${ }^{3}$ como parte de las demandas del movimiento de trabajadores que promovió esas jornadas, que condujeron a la instauración de la II República. ${ }^{4}$

Es perfectamente conocido el hecho de que el gobierno provisional francés surgido de la revolución de febrero de 1848 , mediante una proclama del 25 de febrero, reconoció el «derecho al trabajo" y se comprometió "a dar trabajo a todos los obreros", para lo cual creó, por iniciativa de Louis Blanc, los Talleres Nacionales, en los que el Estado empleó a los franceses desprovistos de un puesto de trabajo. ${ }^{5}$

No obstante, ya antes de estos episodios de la historia de Francia, la idea de un "derecho al trabajo» había sido formulada por la corriente de

2 Aprobada por la Asamblea Nacional Francesa el 26 de agosto de 1789 y sancionada por el Rey, Luis XVI, el 5 de octubre del mismo año.

3 Sin embargo, algunos autores consideran que esta idea ya estuvo presente en la Declaración Constitucional de Derechos del 24 de junio de 1793, aprobada por la Convención Nacional por iniciativa de Maximiliano de Robespierre, en la cual se indicaba que "La sociedad debe la subsistencia a los ciudadanos desgraciados, sea procurándoles trabajo o sea asegurándoles los medios de existir a los que no estén en aptitud de trabajar» (Néstor De Buen Lozano, Derecho del Trabajo, Tomo Primero, Editorial Porrúa, México, 1981, p. 77.)

4 Vid. Rafael Sastre Ibarreche, El derecho al trabajo, Editorial Trotta S.A., Madrid, 1966, p.30

5 Vid. Guillermo Cabanellas, Tratado de Derecho Laboral, Editorial Heliasta SRL, Tomo I, Volumen 1, pp.340-341. 
los llamados "socialistas utópicos» o, más exactamente, pre-marxistas, en particular por Charles Fourier, considerado el "padre» del derecho al trabajo, quien sostuvo que el «derecho al trabajo» es el primero y fundamental de los derechos humanos. ${ }^{6}$ A su vez, para el discípulo de Fourier, Víctor Considérant «el contenido del derecho al trabajo vendría dado por la garantía de un mínimo existencial, al menos en la misma medida en que este era garantizado al hombre salvaje por sus derechos a la caza, a la pesca, al pastoreo y a la recolección"?

A pesar de la significación que tuvo en la revolución de 1848 la demanda del «derecho al trabajo», al elaborarse la Constitución francesa de ese mismo año, este no fue consagrado como un derecho fundamental. El artículo $8^{\circ}$ de este texto se limitó a establecer el deber de la República de «asegurar con asistencia fraternal la existencia de los ciudadanos necesitados, bien procurándoles trabajo en la medida de sus medios, bien prestando ayuda, cuando carezcan de familia, a los que no son capaces de trabajar». ${ }^{8}$

Habrán de transcurrir, desde entonces, más de setenta años hasta que el "derecho al trabajo" aparezca por primera vez formulado en un texto constitucional. El mérito corresponde a la Constitución de Alemania de 191.9, más conocida como la Constitución de Weimar, cuyo artículo $163^{\circ}$ señala en el segundo párrafo: «A todo alemán se ofrece la posibilidad de ganar su sustento mediante el trabajo. En caso en que una ocupación conveniente no pueda serle procurada se le aseguran los medios de existencia necesarios".?

A pesar de la enorme influencia que, sobre todo en el campo de los derechos sociales y económicos, ejerció la Constitución de Weimar, no será sino hasta después de la segunda guerra mundial, cuando esta constitución ya no regía, que algunas importantes constituciones de Europa occidental incluyeron en sus catálogos de derechos el «derecho al trabajo». La primera en hacerlo fue la Constitución francesa de 27 de octubre de 1946 cuyo Preámbulo, que conjuntamente con la Declaración de derechos de 1789 viene a configurar el catálogo de derechos fundamentales,

6 Vid. Rafael Sastre Ibarreche, op.cit., p. 29.

7 Loc.cit.

8 Fórmula ésta semejante a la aprobada por la Convencional Nacional en 1793.

9 B. Mirkine-Guetzevitch, Las nuevas Constituciones del mundo, Editorial España, Madrid, 2da. edición, 1931, p. 89. 
establece que "cualquier persona tiene el deber de trabajar y el derecho de tener un empleom. Poco después, la Constitución de Italia, del 31 de enero de 1947, dispuso, en su artículo $4^{\circ}$, que «la República reconoce a todos los ciudadanos el derecho al trabajo y promueve las condiciones que hagan efectivo este derechon.

Ya en época posterior, otras constituciones europeas como las de Grecia (Art. 22.1), Luxemburgo (Art.11.4), Portugal (Art.59॰) y España (Art. 35.1) reconocen explícitamente el «derecho al trabajo». Las nuevas democracias surgidas en Europa del este, después de la caída del muro de Berlín y el derrumbe del régimen comunista también se inscriben en esta tendencia como es el caso de la Constitución de la Federación Rusa (Art. 37.3) y la de Rumania (Art. 38\%).

En el ámbito latinoamericano, son quince las Constituciones que consagran el derecho de toda persona al trabajo. Estas son: Bolivia, Brasil, Colombia, Costa Rica, Cuba, Ecuador, El Salvador, Guatemala, Honduras, México, Nicaragua, Panamá, Paraguay, Perú y Venezuela.

\section{Su reconocimiento internacional}

El proceso de constitucionalización del derecho al trabajo, fue acompañado por un coetáneo proceso de internacionalización, en la medida que los más importantes instrumentos internacionales sobre derechos humanos lo acogieron en sus textos.

En primer término, debemos mencionar la Declaración Universal de los Derechos Humanos (París, 1948), cuyo artículo 23.1 proclama que «toda persona tiene derecho al trabajo, a la libre elección de su trabajo, a condiciones equitativas y satisfactorias de trabajo y a la protección contra el desempleon. Tras esta declaración, el Pacto Internacional de Derechos Económicos, Sociales y Culturales (1966), reconoce igualmente el «derecho a trabajar» en su artículo 6.1.

En el ámbito continental americano, la Declaración Americana de los Derechos y Deberes del Hombre (Bogotá, 1948), señala en su artículo XIV que «toda persona tiene derecho al trabajo en condiciones dignas y a seguir libremente su vocación, en cuanto lo permitan las oportunidades existentes de empleo". Complementariamente, el Protocolo Adicional a la Convención Americana sobre Derechos Humanos en Materia de Derechos Económicos, Sociales y Culturales, «Protocolo de San Salvador» 
formula, en los artículos $6^{\circ}$ y $7^{\circ}$, una amplia referencia sobre el «derecho al trabajo", sobre la cual volveremos más adelante.

También en el ámbito continental europeo, la Carta Social Europea (18 de octubre de 1961) contiene varias menciones al «derecho al trabajo", en la Parte I, 1 y en la Parte II, 1, señalando entre otras expresiones, que los Estados se comprometen «A proteger de manera eficaz el derecho del trabajador a ganarse la vida mediante un trabajo libremente elegido.» (Parte II, 1,2).

\section{El derecho al trabajo en el constitucionalismo peruano}

Aun cuando se ha considerado que en el Perú la Constitución de 1920 inició tímidamente la constitucionalización del derecho del trabajo ${ }^{10}$ al incluir en su texto normas relativas al trabajo, la recepción constitucional del "derecho al trabajo" se produce tardíamente, pues recién tiene lugar en la Constitución de 1979. Esta consolida de manera muy amplia y clara este proceso pero, además, relieva en forma muy especial el "derecho al trabajo».

Este aparece enunciado como tal en dos partes de la carta: en el Preámbulo, que proclama "Que el trabajo es deber y derecho de todos los hombres y representa la base del bienestar nacional», y en el artículo $42^{\circ}$, correspondiente al Capitulo V «Del Trabajo», que establece: «el Estado reconoce al trabajo como fuente principal de la riqueza. El trabajo es un derecho y un deber social». También en el Título III, relativo al Régimen Económico, se señala que este use fundamenta en principios de justicia social orientados a la dignificación del trabajo como fuente principal de riqueza y como medio de realización de la persona humana», aunque, en este caso, el concepto de trabajo a que se apela es más amplio, en nuestra opinión, que aquel a que refiere el «derecho al trabajo».

La actual Constitución, ha preservado, en términos generales, la fórmula de su antecesora, al consignar en el artículo $22^{\circ}$ : "el trabajo es un deber y un derecho. Es base del bienestar social y un medio de realización de la persona». No obstante, eliminó toda referencia al trabajo en las normas relativas al régimen económico.

10 Vid, Carlos Blancas Bustamante, «La Constitución de 1979 y el Derecho del Trabajo", en: Derecho, revista del Programa Académico de Derecho de la Pontificia Universidad Católica, No 36, Fondo Editorial de la PUCP, Lima, diciembre de 1982, p.10. 


\section{Derecho al trabajo, libertad de trabajo y deber de trabajar}

Antes de profundizar en el contenido del derecho al trabajo, resulta indispensable diferenciarlo de otros conceptos con los que, a menudo, se le confunde, como la «libertad de trabajo» y el «deber de trabajar» que, igualmente, tienen sede constitucional.

\section{La libertad de trabajo}

La libertad de trabajo, a diferencia del «derecho al trabajo» que es un derecho social, forma parte del catálogo tradicional de derechos, también denominados clásicos o de "primera generación». Su contenido está referido a la libre elección y ejercicio del trabajo y de la actividad profesional y económica, y se contrapone al trabajo forzoso y a cualquier sistema que pretenda condicionar el ejercicio de una actividad a la pertenencia a un gremio o corporación. El reconocimiento de la libertad de trabajo fue uno de los instrumentos ideológicos y jurídicos que posibilitaron el desarrollo del capitalismo, al constituirse en factor decisivo para la eliminación del régimen corporativo medieval, que frenaba la expansión de las fuerzas productivas emergentes en la segunda mitad del siglo XVIII. Se sostiene, por ello, que "la libertad de trabajo como premisa y el contrato como instrumento para la canalización de la utilización masiva del trabajo asalariado, conforman las bases jurídicas del primer capitalismo»" ${ }^{11}$

Hitos iniciales en la proclamación de la libertad de trabajo fueron el Edicto de Turgot de 1776 y la Ley Le Chapelier de 1791. El primero, dictado por el Ministro de Luis XVI, Anne Robert Jacques Turgot, tuvo por finalidad abolir el régimen corporativo medieval, conforme al cual para ejercer cualquier oficio, arte, profesión o actividad toda persona debía pertenecer al gremio o corporación respectiva y someterse a sus regulaciones. Es ilustrativo, al respecto, el artículo primero del edicto que define la libertad de trabajar como «libertad para ejercer en nuestro reino la especie de comercio y profesión de artes y oficios que les plazca y hasta ejercer varias $[\ldots] m{ }^{12}$

Posteriormente, ya triunfante la revolución francesa, la Asamblea Nacional, ante el temor del resurgimiento de las corporaciones, aprobó, a

11 Rafael Sastre Ibarreche, op.cit., p. 25.

12 Vid, Guillermo Cabanellas, op.cit., p. 191. 
iniciativa del diputado Yves Le Chapelier, el 14 de junio de 1791, una ley prohibiendo todo tipo de corporaciones así como la reunión de ciudadanos del mismo estado social o profesional, los obreros y compañeros de un arte cualquiera, así como la reglamentación de sus intereses comunes. Esta ley, como es conocido, sirvió a lo largo del siglo XIX (fue derogada en 1884) para impedir la organización de los sindicatos, llegando a considerarse como delito participar en ellos y declararse en huelga.

En las constituciones liberales del siglo XIX y luego en las del siglo XX, la libertad de trabajo aparece explícitamente reconocida, llegando a tener en la libertad de empresa, una de sus manifestaciones más importantes. En nuestros textos constitucionales, la libertad de trabajo tiene asiento a partir de la Constitución de 1826 , cuyo artículo $148^{\circ}$ prescribió que «ningún género de trabajo, industria o comercio puede ser prohibido, a no ser que se oponga a las costumbres públicas, a la seguridad y a la salubridad de los peruanos». En sentido más positivo, la Constitución de 1828 estableció en el artículo $166^{\circ}$ : «es libre todo género de trabajo, industria o comercio; a no ser que se oponga a las costumbres públicas o a la seguridad o a la salubridad de los ciudadanos». Mutatis mutandi, fórmulas semejantes se han sucedido en nuestras constituciones, hasta la de 1979, que en una fórmula más rotunda expresó el derecho de toda persona «a elegir y ejercer libremente su trabajo con sujeción a la ley» (Art. 2.13) y señaló que «a nadie puede obligarse a prestar trabajo personal sin su libre consentimiento y sin la debida retribución» (Art. 420). Esta fórmula, ha sido conservada, casi exactamente, en la vigente constitución (Art. 2.15 y Art. $23^{\circ}$ ).

En cuanto al contenido específico de la libertad de trabajo, que nos permite diferenciarla del "derecho al trabajo", Neves Mujica ha precisado que, respecto de la relación laboral, ésta opera en dos momentos: en su fase inicial y en su fase final. En la primera, en cuanto el trabajador ejerce su libertad para decidir si trabaja o no lo hace, en qué actividad ha de trabajar, si lo hace por cuenta propia o ajena y, en este último caso, al servicio de quién lo hace. En la fase final, la libertad de trabajo le confiere el derecho a dejar el trabajo por su sola voluntad. ${ }^{13}$

Como lo afirma el mismo Neves «[...] la libertad de trabajo protege la voluntad del trabajador de entrar y permanecer, pero no actúa si lo

13 Javier Neves Mujica, "Libertad de trabajo, derecho al trabajo y estabilidad en el trabajo", en: Asesoría Laboral, No 137, mayo, 2002, p.10. 
sacan al trabajador. Puede impedir que se fuerce al trabajador a ingresar o que se le prohiba salir, más no el despido». ${ }^{14}$

En suma, en el momento constitutivo de la relación laboral, el principio de libertad de trabajo se traduce en una libertad de elección del trabajador y se opone a cualquier impedimento o restricción que no tenga una base objetiva, ya sea en el carácter ilícito de la actividad o en la ausencia de condiciones o aptitudes exigidas para el desempeño de un puesto, sin que estas puedan importar, en ningún caso, una forma de discriminación. ${ }^{15}$ Proscribe, igualmente, el trabajo forzoso o impuesto, salvo las excepciones constituidas por el servicio militar obligatorio, el trabajo penitenciario, las obligaciones cívicas y los casos de fuerza mayor, que según diversos instrumentos internacionales no lesionan la libertad de trabajo. ${ }^{16}$ De igual manera, el Convenio 105 de la OIT, ${ }^{17}$ relativo a la abolición del trabajo forzoso, prohibe el trabajo forzoso u obligatorio: a) como medio de coerción o de educación política o como castigo por expresar opiniones políticas u oponerse ideológicamente al orden establecido, b) como método de movilización y utilización de la mano de obra con fines de fomento económico, c) como medida de disciplina en el trabajo, d) como castigo por participar en huelgas y e) como medida de discriminación racial, social, nacional o religiosa. (Artículo $1^{\circ}$ ).

En el momento final de la relación laboral, la libertad de trabajo se contrapone a cualquier decisión de una autoridad o empleador que pre-

\section{Loc. cit.}

15 En este sentido, la libertad de trabajo se emparienta con el derecho a la no discriminación en el empleo, respecto a la cual el Convenio 111 de la OIT precisa que constituye discriminación «cualquier distinción, exclusión o preferencia basada en motivos de raza, color, sexo, religión, opinión política, ascendencia nacional $\mathbf{u}$ origen social que tenga por efecto anular o alterar la igualdad de oportunidades o de trato en el empleo y la ocupación" (Artículo 1, 1, a) ). Precisa el Convenio 111, no obstante, que «las distinciones, exclusiones o preferencias basadas en las calificaciones exigidas para un empleo determinado no serán consideradas como discriminación! (Artículo 1,2.). Este Convenio ha sido aprobado mediante el Decreto Ley No 17687 del 6 de junio de 1970 y ratificado ante la OIT el 30 de agosto de 1970.

16 Cfr. Convenio OIT No 29 (1930) aprobado por el Perú mediante Resolución Legislativa No 13284 del 9 de diciembre de 1959 y ratificado ante la OIT el 1 de febrero de 1960.

17 Este Convenio, sancionado por la OIT en 1957, fue aprobado por el Perú mediante Resolución Legislativa No 13467 del 18 de noviembre de 1960 y ratificado ante la OIT el 6 de diciembre de ese año. 
tendiera obligar al trabajador a permanecer laborando contra su voluntad, salvo los casos en que la ley exige un prudencial plazo de preaviso antes de que el trabajador materialice su retiro o cuando medie un pacto de permanencia, dentro de límites razonables, en caso el empleador haya facilitado o incluso contribuido económicamente, a la formación profesional del trabajador, concediéndole licencia para asistir a cursos en el país o en el extranjero.

En ninguna de dichas fases, la libertad de trabajo comprende, por tanto, la protección o la satisfacción a la expectativa de tener un puesto de trabajo o a la de permanecer en este, respectivamente, aspectos que, como veremos, integran, en cambio, el contenido esencial del «derecho al trabajo».

\section{El «deber de trabajar»}

El trabajo como deber fue consignado en el artículo $42^{\circ}$ de la Constitución de 1979, cuyo texto fue el siguiente: «el Estado reconoce al trabajo como fuente principal de la riqueza. El trabajo es un derecho y un deber social. Corresponde [...]». De esta definición debe retenerse que señala que el trabajo es un deber «social».

La vigente Constitución, en el artículo $22^{\circ}$ establece que «el trabajo es un deber y un derecho. Es base del bienestar social y un medio de realización de la persona».

El «deber de trabajar» aparece, en cierta forma, como la otra cara del "derecho al trabajo", pues solo en la medida que este pueda ser satisfecho $y$, por consiguiente, toda persona tenga la posibilidad efectiva de acceder a un puesto de trabajo, no sería socialmente justificable que el ciudadano en aptitud de trabajar se niegue a hacerlo. Distinta es la situación cuando aquel derecho constituye apenas una lejana expectativa, que muy difícilmente puede satisfacerse para el conjunto de la denominada "población económicamente activa", como acontece sin excepción, en el mundo subdesarrollado e, incluso, en algunos países desarrollados.

Por ello, con agudeza, Martín Valverde apunta que en los Estados que, en su momento, siguieron lo que fue el modelo soviético o de economía estatizada, el "derecho" y el "deber» de trabajar se fundieron en una figura unitaria: «El derecho-deber de trabajar», a cuya satisfacción concurría directamente el Estado mediante políticas de pleno empleo, en su condición no solo de supremo rector de la política económica, sino de principal, sino único, proveedor de puestos de trabajo. Muy diferente es la 
realidad en los países que tienen una economía de mercado, en los cuales el Estado no tiene el control de los mecanismos económicos capaces de crear puestos de trabajo, razón por la que no puede garantizar a todos los ciudadanos la ocupación. ${ }^{18}$ De allí, que se imponga como conclusión obvia la de que si el Estado no puede garantizar el derecho al trabajo de sus miembros, tampoco pueda imponerles el «deber» de trabajar $y$, menos aún, sancionar a quienes no trabajan.

Por ello, existe consenso en señalar que el «deber de trabajar» es una obligación en sentido social o moral, pero de ningún modo en sentido jurídico. Su conceptuación como deber «social» deriva del rol que en las Constituciones suele atribuirse al trabajo, ya sea como «fuente principal de la riqueza" (Const.79, Art.42\%), como "base del bienestar social y un medio de realización de la persona" (Const.93, Art.22 ${ }^{\circ}$ u otras expresiones semejantes, en relación a las cuales la negación a trabajar, pudiendo hacerlo, aparece como una conducta antisocial e insolidaria.

No obstante, si bien la consagración constitucional de un «deber de trabajar" no conlleva una exigencia jurídica de cuyo incumplimiento pudiera derivarse una sanción, se admite que pueda ser exigible por medios indirectos, como lo señala Rubio Correa, quien menciona, entre estos, el tratamiento tributario y el recorte de ciertos beneficios o derechos. ${ }^{19} \mathrm{~A}$ través de ellos, se pretende estimular, indirectamente, a que las personas trabajen y, de ese modo, contribuyan al desarrollo económico y al bienestar.

\section{El derecho al trabajo: su contenido esencial}

\section{Concepto del «contenido esencial»}

Para establecer el significado exacto de cualquier derecho fundamental, enunciado en la Constitución, resulta indispensable determinar su

18 Cfr. Antonio Martín Valverde, «Pleno empleo, derecho al trabajo, deber de trabajar», en: AAVV, Derecho del Trabajo y de la Seguridad Social en la Constitución, Centro de Estudios Constitucionales, Madrid, 1980, pp.193-194.

19 Marcial Rubio Correa, Estudio de la Constitución Política de 1993, Fondo Editorial de la PUCP, Lima, 1999, Tomo 2, p. 201. En el mismo sentido, Martín Valverde, menciona la imposición de un gravamen fiscal adicional a los rentistas renuentes a trabajar o la denegación de prestaciones de desempleo a quienes rechazan una oferta adecuada de empleo» (Antonio Martín Valverde, «Pleno empleo [...]», op.cit, p. 195.) 
"contenido esencial». La referencia a este contenido, aparece, por vez primera en el artículo 19.2 de la Ley Fundamental de la República Federal de Alemania, que señala: «en ningún caso un derecho fundamental podrá ser afectado en su esencia», y es reproducida en el artículo 53.1 de la Constitución española al exigir que toda regulación legal de los derechos y libertades fundamentales respete, en todo caso, su "contenido esencial».

En el contexto de ambas constituciones, se trata de una salvaguarda de los derechos fundamentales ante la eventual actividad reguladora del legislador ordinario, que podría traducirse, de no respetarse esta exigencia, en normas que supongan la restricción o desnaturalización de aquellos. ${ }^{20}$ Desde luego, no solo la actividad del legislador resulta limitada, sino, igualmente la del juez y la administración así como, en general, la de cualquiera que debe aplicar el derecho.

Ahora bien, ¿qué debe entenderse por "contenido esencial» de un derecho fundamental?. Una respuesta sólida y coherente a esta interrogante ha sido formulada por el Tribunal Constitucional español en su Sentencia $11 / 1981$, en la que distingue dos acepciones distintas: la primera, equivale a la naturaleza jurídica de cada derecho, es decir, al modo de concebirlo y configurarlo, en razón de lo cual, el «contenido esencial» está constituido por aquellas facultades o posibilidades de actuación necesarias para que el derecho sea recognoscible en relación al tipo abstracto del derecho, sin lo cual este resultaría desnaturalizado. En otras palabras, debe existir perfecta coherencia entre el concepto abstracto del derecho, preexistente al momento legislativo, y su regulación concreta. ${ }^{21}$

La segunda acepción, explica Fernández Segado, «corresponde a los «intereses jurídicamente protegidos como núcleo y médula del derecho". Se puede entonces hablar de una esencialidad del contenido del derecho para hacer referencia a aquella parte del contenido del mismo que es absolutamente necesaria para que los intereses jurídicamente protegibles, que dan vida al derecho, resulten real, concreta y efectivamente protegidos». ${ }^{22}$

20 «La garantía del "contenido esencial» del derecho supone, pues, la existencia de una barrera insalvable por el propio legislador, que protege un núcleo inmediatamente constitucional y, por lo mismo, irreductible del derecho, que en modo alguno puede ser limitado" (Francisco Fernández Segado, La dogmática de los derechos humanos, Ediciones Jurídicas, Lima, 1994, p. 113.)

21 Vid. Francisco Fernández Segado, op.cit., p. 112.

22 Ibidem, p. 113. 
En el criterio del propio Tribunal español, ambas acepciones no son contradictorias, sino complementarias, pudiendo utilizarse conjuntamente. $^{23}$

Teniendo en cuenta este concepto, podemos ahora abordar la cuestión relativa al contenido esencial del derecho al trabajo.

\section{El derecho al trabajo como norma programática}

La primera, y tradicional, acepción del "derecho al trabajo» lo vincula a la satisfacción de la necesidad de trabajar que tiene toda persona. Como ya vimos, esta acepción tiene un fundamento claro en la realidad histórica, pues en la Francia revolucionaria de 1848 este derecho fue enarbolado por las masas desocupadas y reconocido por el gobierno provisional que lo asumió como una obligación propia, plasmada en ese momento en la creación de los Talleres Nacionales.

Durante el siglo XIX y gran parte del XX esta noción siguió predominando, lo que llevó a catalogar este derecho social como uno de carácter programático o de eficacia mediata o diferida. A diferencia de los clásicos derechos civiles y políticos, concebidos como libertades exigibles y protegibles ante el Estado, los derechos sociales suelen ser concebidos como "derechos-prestación" para cuya efectividad se requiere la actuación positiva del Estado. ${ }^{24}$ Los denominados derechos o normas programáticas se caracterizan porque no "regulan desde el principio e inmediatamente las relaciones y situaciones a que se refieren, sino que ordenan comportamientos públicos destinados a su vez a incidir sobre tales materias; establecen lo que los gobernantes deberán o podrán hacer (y viceversa lo que no podrán hacer) respecto a determinados objetos». 25

Desde esta perspectiva, el derecho al trabajo antes que un derecho subjetivo exigible por cada ciudadano, vendría a configurar una obligación

23 Juan Gorrelli Hernández, El cumplimiento específico de la readmisión obligatoria, Editorial Civitas, Madrid, 1995, p.48.

24 Vid. Carlos Blancas Bustamante, «Estado Social, Constitución y Derechos Fundamentales", en: Constitución, Trabajo y Seguridad Social, Asociación Laboral para el Desarrollo, Lima, 1993, pp. 31-34.

25 Crisafulli, citado por Pablo Lucas Verdú, Curso de Derecho Político, Vol. II, Editorial Tecnos, Madrid, 1986, p. 547. 
social del Estado respecto de aquel sector de personas carentes, y necesitadas, de un puesto de trabajo, la misma que se realizaría mediante políticas, acciones y normas susceptibles de generar esos puestos de trabajo. A esta acepción se refiere Montoya Melgar cuando señala que «la proclamación constitucional del derecho al trabajo no va en rigor más allá de mostrar la intención del Constituyente de que los poderes públicos adopten las medidas necesarias para ir haciendo posible el ejercicio efectivo de tal derecho. Por eso no surgen de la solemne declaración ni derechos subjetivos estrictos de los ciudadanos ni deberes estrictos del Estado en orden a la facilitación de puestos de trabajo, cosa especialmente clara en un sistema económico-social en el que el Estado no asume la función de director y planificador exclusivom. ${ }^{26}$

Como ya se ha señalado anteriormente, al referirnos al «deber de trabajar", el "derecho al trabajo", como exigencia ante el Estado solo puede traducirse en la correlativa obligación de este de realizar una política de pleno empleo, capaz de generar el conjunto de los puestos de trabajo que requiere la PEA. Una exigencia de este tipo fue incluida en el artículo $110^{\circ}$ de la Constitución de 1979 que imponía al Estado la obligación de promover «el desarrollo económico y social mediante el incremento de la producción y de la productividad, la racional utilización de los recursos, el pleno empleo y la distribución equitativa del ingreso".

No obstante, como también se ha expresado, este objetivo no puede, en absoluto, ser garantizado por el Estado en aquellas sociedades que se rigen por una economía de mercado basada en la propiedad privada de los medios de producción y la libertad de empresa, tal como lo proclamaba la Constitución de 1979, pues en tal caso, la creación de puestos de trabajo es, principalmente, función del sector privado, correspondiendo al Estado, únicamente, estimular a este, mediante políticas económicas adecuadas, para que incremente su inversión, lo que habrá de traducirse en la expansión de la oferta de empleo.

Sin embargo, en este aspecto, es decir el del acceso al trabajo, cabe una posibilidad de que el «derecho al trabajo» se individualice $y$, por tanto, se vuelva exigible respecto a determinado puesto de trabajo. Como afirma Neves Mujica, si bien el derecho al trabajo, en el momento inicial de la

26 Alfredo Montoya Melgar, "La protección constitucional de los derechos laborales", en: AA.VV., Derecho del Trabajo y de la Seguridad Social en la Constitución, Centro de Estudios Constitucionales, Madrid, 1980, p. 287. 
relación de trabajo, no juega un papel específico, en cuanto no puede fundamentar el derecho particular de una persona a un puesto de trabajo, podría excepcionalmente ser invocado para exigir el acceso a una ocupación específica "cuando un trabajador postula en un concurso público o interno y resulta seleccionado. En tal hipótesis, tiene el derecho específico a ocupar el puesto objeto de la convocatoriam. ${ }^{27}$

\section{El derecho al trabajo como norma de aplicación inmediata}

La acepción del "derecho al trabajo", como un mero derecho programático, de preceptividad aplazada, que es la perspectiva tradicional desde la cual se ha interpretado sus alcances coincide con el sentido reducido, limitado o restringido del mismo, acuñado por ciertos sectores de la doctrina, conforme al cual aquel estaría referido únicamente a "un genérico mandato del legislador dirigido a intentar conseguir el pleno empleom. ${ }^{28}$ Existe, incluso, una posición que llega a considerarlo inoperante, cuestionando su propia condición de derecho. ${ }^{29}$

Existe, sin embargo, otra posición, que postula un alcance amplio o extenso del «derecho al trabajo», según el cual este, considerado en sí mismo u operando concurrentemente con otros derechos o principios, presentaría una pluralidad de manifestaciones, vinculándose directamente a cuestiones tales como «ingreso al trabajo, ocupación efectiva, cláusulas de seguridad sindical, huelga, extinción del contrato, protección por desempleo, etc.». ${ }^{30}$ Desde una perspectiva similar, se señala que el derecho al trabajo, presenta, además de su aspecto tradicional, uno mas "operativo" que se traduce en «deberes concretos de acción o abstención de los particulares o de los poderes públicos, exigibles judicialmente [...]», entre los cuales se mencionan ulas exigencias de no discriminación en el empleo, de

27 Javier Neves Mujica, op.cit., p. 11. Vid. Al respecto la Sentencia del Tribunal Constitucional de fecha13 de junio de 1997 (Expediente No 008-97-AA/TC-Callao) recaída en la Acción de Amparo seguida por Enrique Ibárcena Rivera contra Corpac S.A., que declara fundada la demanda y ordena se asigne al demandante el puesto que había obtenido mediante concurso interno, previa reposición en la empresa, la cual lo había despedido por exigir se respete el resultado del concurso.

28 Rafael Sastre Ibarreche, op.cit., p. 129.

29 Loc.cit.

30 Rafael Sastre Ibarreche, op.cit., p. 128. 
causalidad del despido individual y de ser informado por oficinas de colocación de las ofertas de empleo existente, las cuales se derivarían directamente del reconocimiento del derecho al trabajo [...], aunque no existiese tutela subconstitucional sobre tales extremos». ${ }^{31}$

Esta concepción amplia ha sido recogida y desarrollada, crecientemente, por la jurisprudencia y la doctrina de numerosos Estados y, también, en importantes instrumentos internacionales. En lo que concierne a nuestro continente, adquiere especial importancia el Protocolo Adicional a la Convención América sobre Derechos Humanos en Materia de Derechos Económicos, Sociales y Culturales o «Pacto de San Salvador", cuyo artículo $7^{\circ}$ señala que "[...] el derecho al trabajo [...] supone que toda persona goce del mismo en condiciones justas, equitativas y satisfactorias, para lo cual dichos Estados garantizarán en sus legislaciones nacionales, de manera particular [...]». Enuncia, a continuación, en los literales a) al h), los derechos a la remuneración, a la libre elección de profesión, a la promoción y al ascenso, a la estabilidad del trabajador en el empleo y otros, los cuales, en el sentido del texto, vendrían a configurarse como verdaderas manifestaciones específicas del derecho al trabajo. La amplitud de esta formulación, que virtualmente coincide con el núcleo normativo del derecho individual del trabajo, podría dar lugar a algún cuestionamiento acerca de la extensión tan amplia que se concede al "derecho al trabajo", por lo que, a reserva de ahondar en su oportunidad tal discusión, por ahora nos centraremos en presentar aquellas expresiones del derecho al trabajo que, tanto la jurisprudencia como la doctrina, suelen vincular o considerar directamente derivadas del mismo.

\subsection{La ocupación efectiva}

Una visión tradicional del contrato de trabajo, de sesgo civilista, que destaca su función de contrato de cambio, consideraba que las obligaciones de las partes se agotaban, por el lado del trabajador, en poner su fuerza de trabajo a disposición del empleador y, por el lado de este, en cancelar a aquel su remuneración, no teniendo, por consiguiente obligación alguna de dar al trabajador una ocupación determinada. ${ }^{32}$

31 Antonio Martín Valverde, Pleno empleo [...], op.cit., p. 204.

32 Cfr. Antonio Martín Valverde, Fermín Rodríguez-Sañudo Gutiérrez y Joaquín García Murcia, Derecho del Trabajo, Editorial Tecnos, Madrid, 1991, p. 500. 
Prescinde esta noción del contrato laboral de consideraciones que van más allá de la simple necesidad del trabajador, que le obliga a vender, cual mercancía, su fuerza de trabajo para conseguir los ingresos que su subsistencia, así como, generalmente, la de su familia, requiere, aspecto este que, desde luego, queda satisfecho —en términos estrictamente jurídicos, que no sociales - con el pago del salario. En efecto, además de un medio para subsistir, el trabajo cumple para la persona otras funciones de índole no económica, pero no por ello menos importantes. Baste recordar que nuestra Constitución predica del trabajo que es «base del bienestar social y un medio de realización de la persona" (Const. 93, Art. 220), lo que conlleva asumir una perspectiva más amplia del trabajo, no solo como factor esencial de la economía, sino, igualmente, como vehículo para que la persona se "realice», esto es, despliegue sus capacidades, potencialidades e iniciativa, y, asimismo, encuentre satisfacción en lo que hace..$^{33}$ De otro lado, pero complementariamente, es indiscutible que el trabajador mediante el trabajo perfecciona y amplia sus conocimientos, profundiza su especialización y adquiere experiencia en la ocupación, oficio o profesión que desempeña, lo que, en definitiva significa que el desempeño efectivo y permanente de una ocupación es requisito esencial de su desarrollo profesional.

De allí que algunas legislaciones, como la española, reconozcan expresamente el derecho del trabajador «a la ocupación efectiva», ${ }^{34}$ el cual, según se ha expresado, «se agota con su «efectividad", es decir, con la obligación empresarial de proporcionar al trabajador los medios e instrumentos que le permitan materializar su prestación laboralm. ${ }^{35}$

Correlativamente, este derecho "genera para el empresario todas aquellas obligaciones de hacer y no-hacer que sean necesarias para su satisfacción: todo aquello que haga posible la efectiva prestación de servicios del trabajador. Así, obliga al empresario a asignar al trabajador puesto concreto de trabajo, dar las órdenes e instrucciones concretas para su ejecu-

33 Para la Doctrina Social de la Iglesia "[...] el trabajo constituye una dimensión fundamental de la existencia del hombre en la tierra», pues mediante él contribuye «a la realización de su humanidad, al perfeccionamiento de esa vocación de persona, que tiene en virtud de su misma humanidad» (Encíclica Laborem Exercens, Juan Pablo II, Num. 4 y 6)

34 Estatuto de los Trabajadores, artículo $4^{\circ}, 2$, a).

35 Alberto Guanche Marrero, El derecho del trabajador a la ocupación efectiva, Editorial Civitas S.A., Madrid, 1993, p. 27. 
ción, proporcionar la información, los útiles y las herramientas necesarias, y cuidar que las circunstancias ambientales sean las adecuadas para la efectiva prestación de servicios. De otra parte, el empresario está obligado a eliminar aquellos obstáculos o impedimentos que repercutan en el desarrollo de la actividad laboral». ${ }^{36}$

La inactividad forzosa del trabajador, derivada de la falta de asignación de tareas o funciones específicas, salvo que esta obedezca a situaciones objetivas, de carácter general y ajenas a la voluntad del empleador, es considerada contraria al "derecho al trabajo" aun cuando ella no afecte la percepción del salario por el trabajador. Es que, la moderna doctrina del contrato de trabajo, atribuye a este, cuando menos, una doble finalidad: la económica, que se satisface con el pago del salario, y la humana y profesional, que solo puede cumplirse si a través del trabajo la persona desarrolla sus capacidades y perfecciona su formación profesional. De allí que el solo pago de su salario a un trabajador al que se obliga a permanecer inactivo, no satisfaga todos los fines del contrato de trabajo y vulnere, por consiguiente, el derecho al trabajo.

Se ha destacado, además, los evidentes perjuicios que dicha conducta empresarial acarrea al trabajador por «[...] entrañar además un atentado contra su dignidad personal al verse privado de un instrumento esencial en la realización de su personalidad. La elevación de los valores morales al primer plano del orden jurídico, quedarían directamente violentados si el trabajador se viera forzado a mantener una ociosidad incompatible con su deber constitucional de trabajar [...]). ${ }^{37}$

También es importante la vinculación del derecho a la ocupación efectiva con la protección de la profesionalidad del trabajador, en la medida que la inactividad de este afecta su promoción y formación profesional. De hecho, el trabajador forzado a la inactividad es separado de la dinámica de la empresa y postergado en sus expectativas de promoción y ascenso, ya que difícilmente podrá reunir las calificaciones requeridas para ello, vinculadas al desempeño efectivo de una función. De la misma manera, quedará marginado de la formación profesional, que es ingrediente necesario para su futura promoción. Incluso, en la perspectiva de dejar la empresa, una previa inactividad prolongada puede causar la pérdida o disminución significativa de su competitividad en el mercado de trabajo.

36 Antonio Martín Valverde y otros, Derecho del [...], op.cit., p. 501.

37 Alberto Guanche Marrero, op.cit., pp.34-35. 
Se relaciona, igualmente, la ocupación efectiva con la interdicción de la discriminación, en la medida que puede considerarse que negar trabajo a uno o varios trabajadores mientras los demás que integran la empresa lo tienen, constituye una conducta discriminatoria. ${ }^{38}$

Por estas razones, se ha puesto de relieve que así como el desconocimiento de este derecho comporta la vulneración del derecho fundamental al trabajo, de la misma manera genera, como consecuencia directa, la vulneración de otros derechos laborales, como a la promoción y formación profesional. ${ }^{39}$

La implicación del trabajo, como actividad humana, con otros valores y principios constitucionales, determina que además de considerarse al "derecho al trabajo» como la fuente directa e inmediata del derecho a la ocupación efectiva, este pueda encontrar, concurrentemente, apoyo en aquellos, configurándose, de esta manera, como un derecho tributario de diversos preceptos constitucionales, todos ellos organizados en torno a la idea central de la dignidad humana y del trabajo como medio de realización de la persona.

En nuestro ordenamiento, el derecho a la ocupación efectiva apenas ha logrado reconocimiento en la Ley del Régimen Laboral del Futbolista Profesional (Ley No 26566), cuyo artículo 7o, inciso d) lo incluye entre los derechos del futbolista profesional, precisando que en virtud de este el futbolista no puede, salvo en caso de sanción o lesión, ser excluido de los entrenamientos y demás actividades instrumentales o preparatorias para el ejercicio de la actividad deportiva.

\subsection{El derecho al trabajo y la conservación del empleo}

El hito inicial de este proceso se encuentra en la Sentencia No 45 del Tribunal Constitucional italiano, del 9 de junio de 1965, que estableció que el artículo 2,118 del Código Civil, que permitía el despido ad nutum, con la simple exigencia formal de un preaviso, debía interpretarse conforme a los principios de la Constitución, especialmente los artículos $4^{\circ}$ (derecho al trabajo) y $41^{\circ}$ (ejercicio de la libertad económica conforme a la utilidad social) de ésta, en el sentido de la conservación del puesto de

38 Ibidem, p. 36.

39 Ibidem, pp. 36-37. 
trabajo. ${ }^{40}$ La trascendente decisión del Tribunal italiano, produjo casi de inmediato un cambio en la legislación laboral al aprobarse el 15 de julio de 1966 la Ley No 604 que introdujo el «justificado motivo» de despido, suprimiendo así el despido ad nutum. Continuando este proceso, en 1970 , se dictó el Estatuto del Trabajador, Ley No 300, que estableció la estabilidad real en el empleo al prever en su artículo $18^{\circ}$ la readmisión obligatoria del trabajador despido sin justa causa. ${ }^{41}$

La doctrina española se decantó a favor de este criterio a la hora de realizar la interpretación del artículo 35.1 de la Constitución de 1978, que establece: «todos los españoles tienen el deber de trabajar y el derecho al trabajo [...]». Analizando esta norma y su relación con la libertad de empresa, Martín Valverde sostiene que "[...] las limitaciones más clásicas de la autonomía empresarial como consecuencia del reconocimiento del derecho al trabajo son las que se refieren a la exigencia de una causa grave para la justificación de los despidos individuales»". ${ }^{42}$ En la misma dirección, Montoya Melgar reconoce la existencia de una segunda acepción del derecho al trabajo que conceptúa a este como una «libertad actual e inmediata en el trabajon frente a quienes pretendan vulnerarla. Concluyendo su razonamiento, afirma este autor, que uno de los efectos de esta acepción más restringida del derecho al trabajo consiste en que «el despido injustificado encontraría un importante freno en el derecho al trabajo, cuya recta interpretación seguramente debiera jugar a favor de la readmisión forzosa del despedido sin causa». ${ }^{43}$

La jurisprudencia del Tribunal Constitucional español recoge, finalmente, esta doctrina en la Sentencia 22/1981, del 2 de julio de ese año. En esa sentencia el TC precisa que «[...] el derecho al trabajo no queda

40 Vid. Alessandro Pizzorusso, Lecciones de Derecho Constitucional, Centro de Estudios Constitucionales, Madrid, 1984, p. 178. También, Juan Antonio Sagardoy, La terminación del contrato de trabajo, Instituto de Estudios Económicos, Madrid, 1980, p. 86. Téngase presente que el artículo $41^{\circ}$ de la Constitución italiana señala que "La iniciativa económica privada es libre. No puede desarrollarse contrariamente a la utilidad social o de manera que atente a la seguridad, a la libertad, a la dignidad humanas».

41 Recientemente, en virtud de un acuerdo entre el Gobierno y la principal central sindical de Italia, esta norma ha quedado temporalmente en suspenso, con carácter experimental, en tanto se implementan medidas compensatorias, como la mejora de las prestaciones por desempleo.

42 Antonio Martín Valverde, Pleno empleo [...], op. cit., p. 202.

43 Alfredo Montoya Melgar, op.cit., pp. 287-288. 
limitado a la libertad de trabajar, sino que implica algo más: conlleva el derecho a un puesto de trabajo y, en este sentido, adoptaría una doble faceta. Por un lado - faceta individual concretada en el artículo 35.1 $\mathrm{CE}-$, implicaría el derecho de todas las personas que acrediten la capacidad exigida para ello a un determinado puesto de trabajo y el derecho a la estabilidad en el empleo, esto es, a no ser despedido sin la concurrencia de causa justa. Por otro - faceta colectiva que emana del artículo 40.1-, supondría un mandato dirigido a los poderes públicos para que realicen una política de pleno empleom. ${ }^{44}$

Más adelante, en otra importante Sentencia, del 27 de enero de 1994, el Tribunal Constitucional español señaló que: "[...] la inexistencia de una reacción adecuada contra el despido o cese debilitaría peligrosamente la consistencia del derecho al trabajo y vaciaría al derecho que lo regula de su función tuitiva".

La doctrina española señala, por ello, que en su vertiente individual el derecho al trabajo se concreta uen el derecho a un puesto de trabajo, lo cual significa el derecho a acceder al trabajo en igualdad de condiciones, esto es, la prohibición de discriminaciones en el empleo, y el derecho a la estabilidad en el mismo, que se traduce en la necesaria concurrencia de justa causa para efectuar el despido». ${ }^{45}$

En suma, en su aspecto individual, el derecho al trabajo supone la vigencia del principio de causalidad como exigencia ineludible para la validez del despido, descartando, de este modo, del ordenamiento jurídico el despido ad nutum o incausado, entendiendo por tal aquel en el cual la sola expresión de voluntad del empleador es considerada suficiente para extinguir la relación laboral. En este sentido, «la supresión de la facultad del empleador de despedir libremente posee así, se ha dicho, no solo un valor sistemático o de principio, sino que refleja también, de modo emblemático, una concreta opción política de garantía, tanto del derecho a la ocupación, en su contenido económico y profesional, como de la dignidad social\%. ${ }^{46}$

Se ha afirmado también, que en el derecho al trabajo pueden distinguirse dos facetas, teniendo en cuenta quien sea el sujeto pasivo frente al

44 Rafael Sastre Ibarreche, op. cit., pp. 131-132.

45 Ibidem, pp.133-134.

46 E. Ghera, Tutela reale e tutela obbligatoria: il licenzoamiento, p. 464, citado por Rafael Sastre Ibarreche, op. cit. p. 243. 
que puede ejercerse o que debe satisfacerlo: la pública y la privada. En su aspecto público, el sujeto pasivo es el Estado, y el derecho se traduce en el deber de este de fomentar el empleo; en su aspecto privado, el sujeto pasivo es el empleador y «se centraría en el derecho del trabajador a ocupar su puesto de trabajo hasta que haya una justa causa por la que pierda su empleom. ${ }^{47}$ Este enfoque no es, en modo alguno, opuesto al anterior sino coincidente pues la faceta pública vendría a ser el aspecto colectivo del derecho y la privada se identificaría con el aspecto individual.

Por su parte, en la doctrina latinoamericana, De Buen afirma el sentido amplio de este derecho: «el derecho al trabajo presenta, sin duda alguna, varias formas de manifestarse. Podríamos hablar, en primer término, del derecho a adquirir un empleo. En segundo lugar, del derecho a conservar un empleo». ${ }^{48}$ Respecto a esta última manifestación señala que «se traduce en una fórmula que podría ser la siguiente: todo trabajador tiene derecho a conservar el empleo, salvo que hubiere una causa justa para privarle de él. Este principio se identifica como el de la estabilidad en el empleo.» ${ }^{49}$

Y, en este ámbito, como antes lo señalamos, el derecho al trabajo, está consagrado en el "Protocolo de San Salvador», el cual, tras enunciar en su artículo $6^{\circ}$ el contenido esencial del "derecho al trabajo», desarrolla in extenso todos sus alcances en el artículo $7^{\circ}$ que dice:

"Los Estados Partes en el presente Protocolo reconocen que el derecho al trabajo al que se refiere el artículo anterior, supone que toda persona goce del mismo en condiciones justas, equitativas y satisfactorias, para lo cual dichos Estados garantizarán en sus legislaciones, de manera particular:

[...]

d) La estabilidad de los trabajadores en sus empleos, de acuerdo con los características de las industrias y profesiones y con las causas de justa separación. En casos de despido injustificado, el trabajador tendrá derecho a una indemnización o a la readmisión en el empleo o a cualesquiera otra prestación prevista por la legislación nacional.»

47 Juan Gorrelli Hernández, El cumplimiento específico de la readmisión obligatoria, Editorial Civitas S.A., Madrid, 1995, pp. 34-35.

48 Néstor De Buen Lozano, Derecho del [...], op.cit., p. 80.

49 Loc. cit. 
De este modo en el pensamiento del Protocolo, "derecho al trabajo" y "estabilidad en el empleo" son conceptos implicantes, siendo el segundo una de las manifestaciones concretas del primero.

Específicamente, la "estabilidad en el empleo" a que se refiere el Protocolo se traduce en la exigencia de una causa de «justa separación» para la validez del despido, de lo que se deduce, sin mayor dificultad, que este instrumento descarta el despido sin causa, o ad nutum, por ser contrario al derecho al trabajo. En tal sentido, el Protocolo de San Salvador viene a dar sustento, en el ámbito de la normativa internacional, a la tesis amplia del derecho al trabajo que, superando su concepción tradicional de alcance restringido, extiende sus efectos a la protección del trabajador contra el despido incausado.

Al haber sido ratificado por el Estado peruano y en aplicación de la regla de interpretación de los derechos fundamentales conforme a los tratados y acuerdos sobre derechos humanos, ${ }^{50} \mathrm{el}$ Protocolo constituye fuente obligatoria para la interpretación del derecho al trabajo, en la medida que este figure reconocido en el catálogo de derechos fundamentales de nuestra Constitución, tal como ocurre en el momento actual con el artículo $22^{\circ}$ de la ley fundamental y habrá de suceder en el futuro según el artículo $27^{\circ}$ del proyecto. En tal virtud, el derecho peruano, por la vía del Protocolo de San Salvador, incorpora el concepto de "estabilidad en el empleo", entendido, a su vez, como la exigencia de una causa justa para la validez del despido, o "principio de causalidad" del despido.

Tal concepción amplia del "derecho al trabajo» ha sido, igualmente, recogida por la jurisprudencia de nuestro Tribunal Constitucional, en su sentencia del 11 de julio de $2002^{51}$ en la que expresa :

«El derecho al trabajo está reconocido por el artículo $22^{\circ}$ de la Constitución. Este Tribunal estima que el contenido esencial de este derecho constitucional implica dos aspectos. El de acceder a un puesto de trabajo, por una parte $y$, por otra, el derecho a no ser despedido

50 Esta regla figura en la Cuarta Disposición Final y Transitoria de la Constitución de 1993, pero en el texto de la nueva Constitución estará consagrada en el Artículo II del Título Preliminar.

51 Expediente No 1124-2001-AA/TC, en proceso seguido entre el Sindicato Unitario de Trabajadores de Telefónica del Perú y la Federación de Trabajadores de Telefónica del Perú contra esta empresa en relación al despido de más de quinientos trabajadores. 
sino por causa justa. Aunque no resulta relevante para resolver la causa, cabe precisar que, en el primer caso, el derecho al trabajo supone la adopción por parte del Estado de una política orientada a que la población acceda a un puesto de trabajo; [...]. El segundo aspecto del derecho es el que resulta relevante para resolver la causa. Se trata del derecho al trabajo entendido como proscripción de ser despedido salvo por causa justa».

Así pues, nuestro TC, consagra la interpretación amplia del «derecho al trabajo", en virtud de la cual este se extiende a la protección del empleo, tolerando la pérdida del mismo únicamente cuando medie una causa justa, legalmente establecida y debidamente comprobada. En tal virtud, el "derecho al trabajo", incluye el denominado "principio de causalidad" cuando opera respecto del momento extintivo de la relación laboral, radicando en la exigencia del respeto a este la eficacia de aquel derecho.

\section{El derecho al trabajo en el proyecto de reforma constitucional}

El derecho al trabajo se encuentra reconocido en el artículo $27^{\circ}$ del Proyecto de Ley de Reforma Constitucional, en los siguientes términos:

«El trabajo es un deber y un derecho, base del bienestar social y un medio de realización de la persona.

El trabajo, en sus diversas modalidades, es objeto de protección por el Estado, en especial el de la madre y el menor de edad. El Estado erradica toda forma de trabajo prohibido por la ley.

El despido requiere de causa justificada señalada en la ley. En caso de despido injustificado el trabajador tiene derecho a una indemnización o a la readmisión en el empleo o a cualquier otra prestación, en la forma prevista por la ley. Es nulo el despido que agravia derechos fundamentales reconocidos por esta Constitución."

De esta formulación destaca un cambio de enfoque, acerca del contenido del derecho al trabajo, que establece una nítida diferencia con las dos constituciones precedentes (1979 y 1993), pues acogiendo la más moderna doctrina y las orientaciones del Protocolo de San Salvador, el artículo $27^{\circ}$ asume, decididamente, como contenido el aspecto individual o pri- 
vado, según se prefiera, del derecho al trabajo, esto es su proyección sobre el momento extintivo de la relación laboral, estableciendo la exigencia de causa justificada como requisito para la validez del despido. Repárese que en la Constitución de 1979 el derecho a la estabilidad en el trabajo fue enunciado en el artículo $48^{\circ}$ y el derecho al trabajo en el artículo $42^{\circ}$, y que la de 1993, reconoce a este último en su artículo $22^{\circ}$ y el derecho a la protección contra el despido arbitrario en el $27^{\circ}$. Y, si bien, la interpretación sistemática de dichas normas conducía a una conclusión no muy diferente de la que puede extraerse del artículo $27^{\circ}$ del Proyecto, ${ }^{52}$ es evidente que el enfoque adoptado por este facilita la labor interpretativa y descarta toda polémica acerca de si el principio de causalidad del despido forma parte, o no, del derecho al trabajo.

\section{El derecho al trabajo y el despido injustificado o nulo}

\subsection{El despido injustificado y la estabilidad en el empleo}

La norma proyectada establece el núcleo esencial de la futura regulación normativa del régimen del despido. Afirma, en primer lugar, como ya se dijo, el principio de causalidad del despido, al establecer que «el despido requiere de causa justificada [...]» y el requisito de la tipicidad y legalidad de la causa justificada al agregar que esta debe ser «señalada en la ley», expresión que establece una reserva legal expresa en materia de precisar cuales han de ser las causas justificativas del despido.

La interpretación de esta norma, - una vez aprobada la reforma- deberá efectuarse, necesariamente, a la luz del Protocolo de San Salvador, cuyo artículo $7^{\circ}$ inciso d) guarda directa conexión con el artículo $27^{\circ}$ proyectado, por referirse ambos al despido.

Como ya tuvimos ocasión de analizar, el referido tratado consagra el derecho a la "estabilidad en el empleo», entendiendo por ésta la exigencia de una causa de justa separación como requisito para la validez del despido. En tal sentido, la regulación legal del despido, para ser conforme con la Constitución, deberá tener como contenido primigenio y esencial la vigencia del "principio de causalidad» o, dicho en otros términos, la proscripción del despido incausado.

52 Vid. Carlos Blancas Bustamante, «El derecho al trabajo y el despido arbitrario. A propósito de una sentencia del Tribunal Constitucional», en: Ius et Veritas, Año XIII, No 25, Lima, noviembre de 2002, pp. 268-280. 
De la interpretación del artículo $27^{\circ}$ del Proyecto, efectuada conforme a las normas del Protocolo de San Salvador (arts $6^{\circ}$ y $7^{\circ}$ ), fluye nítidamente que este precepto consagra la «estabilidad en el empleo» en cuanto esta institución supone la exigencia de "causa justa" como elemento legitimador del despido y, en consecuencia, excluye la posibilidad de que este pueda efectuarse válidamente basándose en el mero arbitrio del empleador. De este modo, la "estabilidad laboral" se contrapone al "despido ad nutum", que reconoce en la sola voluntad - incluso incausada - del empleador el factor legitimador del despido.

No obstante, la interpretación del artículo $27^{\circ}$ del Proyecto, a la luz del Protocolo, no conduce a "constitucionalizar" un régimen específico de estabilidad laboral - absoluta o relativa -, pues ambas normas son plenamente coincidentes, tras establecer el principio de causalidad, en dejar a criterio del legislador ordinario efectuar esta opción, centrada - como se sabe-en definir la medida reparadora - reposición o indemnización aplicable frente a un despido injustificado, entendiendo por tal aquel basado en una causa justa que el empleador no puede probar en juicio. Pero, en modo alguno, esta libertad de opción concedida por el constituyente al legislador respecto al régimen de estabilidad laboral, conlleva la posibilidad de eliminar la estabilidad misma mediante la supresión de la exigencia de una causa justa para la validez del despido.

En tal sentido, la opción entre un sistema de estabilidad relativa, que solo contemple la indemnización, u otra prestación, como respuesta a la injustificación del despido o uno de estabilidad absoluta que prevea la reposición del trabajador en el mismo supuesto, se convierte, como en rigor es, en una cuestión de política legislativa, que habrá de definirse en función de las circunstancias sociales y económicas prevalecientes en un momento determinado, sin que, por otro lado, la elección del legislador vaya a significar que esa sea la única interpretación posible del texto constitucional ni, por tanto que no sea susceptible de variar en atención al cambio de aquellas circunstancias.

\subsection{El despido nulo, lesivo de derechos fundamentales}

Asimismo, el artículo $27^{\circ}$ del Proyecto califica como nulo el despido que agravie los derechos fundamentales reconocidos por la Constitución. Se recoge, en esta forma, una figura que en los últimos tiempos ha tenido creciente reconocimiento en la jurisprudencia y la legislación de numero- 
sos países, al destacarse la relevancia "constitucional» del despido en cuanto este puede servir como vehículo o instrumento para la lesión de los derechos constitucionales del trabajador. ${ }^{53}$

Por ello, se ha destacado que en el despido nulo no es que "falte» la causa, como de ordinario ocurre en los despidos injustificados - al no probar el empleador la existencia de la imputada-, «sino que existe una causa real pero ilícita que opera como límite constitucional intrínseco e infranqueable de la facultad que el legislador confiere al empleador en orden a la extinción del contrato de trabajo por su decisión unilateral $»{ }^{54}$

Esa "causa", presente y efectiva materialmente pero inadmisible jurídicamente, supone la lesión de cualquiera de los derechos fundamentales del trabajador. Obsérvese que en el texto del precepto bajo comentario, la nulidad del despido no se predica únicamente respecto de los derechos "laborales" específicos del trabajador sino con relación a todos los que como persona y ciudadano le corresponden. Ello abarca, en especial, aquellos que integran lo que Alonso Olea denomina la «versión laboral de los derechos fundamentales", "en el sentido de que pueden emerger u ocurrir, y aún ocurrir con manifestaciones típicas, en conexión con las relaciones individuales y colectivas de trabajo». ${ }^{55}$ Se incluye en esta "versión» entre otros, con especial incidencia en el ámbito de la relación laboral, el derecho a la libertad ideológica y religiosa, a la intimidad personal, a la reunión, a la libre expresión de las ideas, a obtener la tutela judicial efectiva y a la presunción de inocencia, sin que este enunciado tenga más valor que el ilustrativo pues, aunque existan unas hipótesis más probables que otras, en verdad cualquier derecho fundamental puede ser afectado mediante el despido siendo lo relevante, en esta materia, la concepción según la cual el contrato de trabajo, y la relación entre empleador y trabajador que nace de este, no constituye un campo o zona segregada de la aplicación de la Constitución o del ejercicio de los derechos que esta consagra,

53 Vid. Carlos Blancas Bustamante, El despido en el derecho laboral peruano, Ara Editores, Lima, 2002, Capítulo Quinto. También, Elmer Arce Ortiz, La nulidad del despido lesivo de derechos constitucionales, Fondo Editorial de la PUCP, Lima, 1999.

54 José Luis Monereo Pérez y María Nieves Moreno Vida, «Forma y procedimientos del despido disciplinario", en: AAVV, La reforma del Estatuto de los Trabajadores, Editoriales de Derecho Reunidas, Madrid, 1994, p. 394.

55 Manuel Alonso Olea, Las fuentes del Derecho, en especial del Derecho del Trabajo según la Constitución, Editorial Civitas, Madrid, 1990, p. 28. 
razón por la cual las conductas que en este ámbito sean lesivas de aquellos deben merecer la sanción de la nulidad. ${ }^{56}$

Por ello, en sentido coincidente, el texto constitucional proyectado señala en su artículo $29^{\circ}$ que «en la relación de trabajo es nula toda condición que impida el ejercicio de los derechos fundamentales».

Al vincular directamente la nulidad con la lesión a cualquier derecho fundamental, el artículo $27^{\circ}$ del Proyecto plasma una concepción amplia del despido nulo, superando la configuración mutilada que del mismo contiene la legislación actual. ${ }^{57}$ Por otro lado, la "constitucionalización" de esta figura debe verse, antes que como una extensión de las normas de Derecho Laboral contenidas en la Constitución, como la reafirmación de los principios de «supremacía constitucional» $\mathrm{y}$ «mayor valor» de los derechos fundamentales, propios del Estado de Derecho, conforme a los cuales este no pueden consentir en la existencia de zonas aisladas o inmunes a la aplicación y ejercicio de aquellos.

El reconocimiento constitucional del despido nulo y su diferenciación del "despido injustificado" o incausado, conlleva que en este supuesto proceda la reposición del trabajador, como medida reparadora necesaria, toda vez que lo que es jurídicamente nulo no produce efecto alguno. Esta solución, que es la que actualmente establece la ley peruana, y las legislaciones extranjeras que regulan esta clase de despido, encuentra, además, sólido fundamento en el hecho de que por implicar la lesión de derechos fundamentales tal despido puede ser impugnado mediante la Acción de Amparo, la misma que conlleva la aplicación de mecanismos de tutela restitutoria, esto es, como lo señala el artículo $1^{\circ}$ de la Ley de Habeas Corpus y Amparo, «la reposición de las cosas al estado anterior a la violación o amenaza de violación de un derecho constitucional.» Cabe recordar, al respecto, que la doctrina constitucional es categórica en señalar que en materia de protección a los derechos fundamentales corresponde a los

56 La Sentencia del Tribunal Constitucional del 7 de noviembre de 2002, Expediente No 2409-2002-AA/TC, precisa que «una lectura sistemática de la Constitución y una aplicación integral de las normas relativas a los derechos fundamentales no admite «zonas de indefensión" (Fundamento 1,b) y, mas adelante señala que no puede "alegarse ningún tipo de zona invulnerable a la defensa de la constitucionalidad o la protección de los derechos humanosm".

57 Vid. Carlos Blancas Bustamante, El despido en [...], op.cit., p. 290 y ss. 
órganos jurisdiccionales dispensar al afectado una pronta y efectiva tutela restitutoria. $^{58}$

\section{El derecho al trabajo y el fomento del empleo}

Aquel aspecto o contenido del derecho al trabajo que tradicionalmente se ha puesto de relieve como su contenido único o principal, aparece ahora regulado en el artículo $28^{\circ}$ del proyecto de Ley de Reforma Constitucional, que se refiere a la obligación del Estado de adoptar políticas y promover condiciones para «el fomento del trabajo decente, equidad en el acceso al empleo, capacitación, formación profesional, productividad y formalización de las relaciones de trabajo".

Este precepto del proyecto encierra, en verdad, varias cuestiones vinculadas a la política de empleo, como expresión o, mejor dicho, deber del Estado directamente derivado del derecho ciudadano al trabajo. El primero de estos deberes es el de fomentar el empleo, habiendo omitido toda referencia a una política de "pleno» empleo, habida cuenta de las obvias dificultades que implica alcanzar este objetivo y de la cuasi imposibilidad de que el Estado se obligue a ello en el marco de una economía de mercado, regida por la libertad de empresa, en que aquel no cuenta con los mecanismos apropiados para la creación directa de empleo. Su función, al respecto, es, por tanto, indirecta, limitándose a "fomentar» el trabajo, mediante la adopción de políticas económicas y sociales y normas legales que creen condiciones favorables para que, principalmente, sea el sector privado el que genere los puestos de trabajo requeridos.

El empleo a «fomentar» es el "trabajo decente», exigencia esta que desestima la creación de empleo precario, es decir, aquel que no reúne las condiciones mínimas de seguridad, remuneración y protección social establecidas en estándares generalmente aceptados.

Las políticas y condiciones que debe promover el Estado para que exista "equidad en el acceso al empleo" dicen relación con una decidida proscripción de la discriminación, cualquiera sea su motivo, en la fase constitutiva o inicial de las relaciones de trabajo. Al respecto, esta disposición habrá de interpretarse y aplicarse en consonancia con el Convenio

58 Vid. Héctor Fix Zamudio, La protección procesal de los derechos humanos ante las jurisdicciones nacionales, Editorial Civitas, Madrid, 1982, p. 49. 
$\mathrm{N}^{\circ} 111$ de la OIT sobre «discriminación en materia de empleo y ocupación", así como otros instrumentos internacionales relativos a la discriminación. ${ }^{59}$

Las referencias a las políticas de capacitación, formación profesional y productividad (entiéndase: fomento de...) deben verse como acciones de naturaleza educativa, complementarias o integradas en la política de empleo en cuanto se dirigen a ofrecer oportunidades de preparación, perfeccionamiento y elevación de su nivel profesional o técnico a los trabajadores para mejorar sus posibilidades de acceso al empleo, en un mercado crecientemente competitivo, en que la calificación ocupacional juega, cada vez más, un rol preponderante. De este modo, el Estado promueve el empleo actuando no solo sobre la oferta de trabajo, principalmente a través de políticas económicas, sino, también, sobre la demanda de aquel, mediante políticas educativas, al involucrarse en la capacitación y perfeccionamiento de los trabajadores.

En último término, la incorporación al texto constitucional de la obligación estatal de promover la "formalización de las relaciones de trabajo" entraña una vocación de respuesta a la grave situación de la informalidad que al finalizar el año 2001 representaba en el Perú el 52.9\% del empleo no agrícola y sin considerar las personas empleadas en el servicio doméstico. Las relaciones de trabajo en dicho sector, especialmente en las microempresas, que representan, el $18.8 \%$ del empleo no agrícola, son extremadamente precarias y la exigencia de su formalización conduce, básicamente, a superar estas condiciones mediante su inserción en el marco legal e institucional, para lo cual el Estado debe desarrollar una política que les permita compensar los mayores costos derivados de las obligaciones laborales que deberán cumplir, con incentivos adecuados de carácter tributario y crediticio, así como capacitación y asesoramiento para la gestión empresarial. Desde luego, la opción de conseguir esta «formalización" vía la creación de un régimen laboral especial, que suponga la devaluación de los derechos y beneficios establecidos en el régimen general, creando así una suerte de trabajadores de segunda clase, no sería, en modo alguno apropiada ni constitucional, porque entraría en conflicto directo con las

59 Especialmente relevantes al respecto son la «Convención Internacional sobre la Eliminación de todas las Formas de Discriminación Racial», de las Naciones Unidas (1965) y la "Convención sobre la eliminación de todas las formas de discriminación contra la Mujer», Naciones Unidas (1979), ambas ratificadas por el Perú en 1971 y 1982, respectivamente. 
normas relativas a la igualdad de trato, de oportunidades y no discriminación, así como la igualdad ante la ley. 